\title{
Change in obstructive pulmonary function as a result of cumulative exposure to welding fumes as determined by magnetopneumography in Japanese arc welders
}

Toshio Nakadate, Yoshiharu Aizawa, Takashi Yagami, Yi-Qin Zheg, Makoto Kotani, Kouichi Ishiwata

\begin{abstract}
Objectives-To examine the effect of chronic exposure to welding fumes on pulmonary function by a direct estimate of fumes accumulated in the lungs.

Methods-The strength of the residual magnetic field of externally magnetised lungs (LMF) was used as an estimate of fumes accumulated in the lungs. The results of forced spirometry manoeuvres obtained in 143 of 153 male welders in the original sample were cross sectionally evaluated according to LMF. Seven conventional forced spirogram indices and two time domain spirogram indices were used as pulmonary function indices, and height squared proportional correction was performed when necessary.

Results-The distribution of LMF values was considerably skewed towards positive. There was a weak but significant positive relation between age and log transformed LMF. Obstructive pulmonary function indices correlated well with LMF. After adjustment for age and smoking, however, a significant association with LMF was only found with percentage rate of forced expiratory volume in one second $\left(\mathrm{FEV}_{1} \%\right)$ divided by forced vital capacity (FVC) and mu, an average component of assumed time constant distribution of lung peripheral units. Neither FVC nor vital capacity (VC), as indices of restrictive disorders, showed a significant association with LMF. Based on the results of multiple regression analyses, a $0.6 \%$ decrease in $\mathrm{FEV}_{1} \%$ and 0.039 unit increase in mu were expected for each doubling of LMF.

Conclusion-Obstructive changes in pulmonary function were found to be related to level of cumulative exposure to welding fume in male Japanese arc welders after controlling for age and smoking, assuming that LMF adequately reflects accumulation of welding fumes in the lungs. (Occup Environ Med 1998;55:673-677)
\end{abstract}

Keywords: welding; obstructive airway disease; magnetopneumography

In most developed countries, increases in mortality from chronic obstructive pulmonary diseases (COPDs) have been found to be associated with aging of the population. ${ }^{1}$
Although the reason for this is still unclear, the work environment is suspected of contributing to the occurrence and course of COPD. ${ }^{2}$

There are many workers primarily engaged in welding work in most developed countries. Welding work is associated with exposure to various fumes and gases that are potentially harmful to the respiratory system. ${ }^{3}$ Fortunately most previous studies dealing with the chronic respiratory effects of welding work have not shown convincing evidence for deterioration of pulmonary function, ${ }^{4-8}$ and thus it seems to be generally accepted that ordinary accumulation of welding fumes in the lungs is unrelated to COPD. ${ }^{9}$ Nevertheless, there have been several reports suggesting subtle but significant obstructive change in the peripheral regions of the lungs as a result of welding. ${ }^{10-12}$

One important aspect of this issue that remains to be elucidated is dose related characteristics. Most studies have simply compared welders as a whole with their referents. Several have attempted dose related analysis but have generally used only exposure during the study period or such an indirect estimate of cumulative dose as duration of employment or type of welding. We therefore conducted this study to elucidate the dose related characteristics of the possible association between chronic accumulation of welding fumes in the lungs and change in obstructive pulmonary function with magnetopneumography to estimate the amount of accumulation of welding fumes in the lungs.

\section{Subjects and methods}

SUBJECTS

Study subjects were 153 male electric arc welders employed in a factory producing tractors, loaders, and hydraulic excavators. All subjects gave informed consent before joining this study. They were examined in 1994 by forced spirometry, magnetopneumography, and questionnaire interview. The workers were generally engaged in electric arc welding of mild steel with an inert gas shield in large factory buildings with a high roof. All of the welding workplaces were equipped with artificial exhaust emission devices. Welding was never performed in small, confined spaces. Although some fluctuations were recognised, the air quality of the work environment was fairly well maintained during the year of the study. The mean concentration of respirable particulates recorded in 1994 was around $0.5 \mathrm{mg} / \mathrm{m}^{3}$, about 
half the maximum allowable concentration for iron oxide dust recommended by the Japan Society for Occupational Health. ${ }^{13}$ Also, the workers had been strongly encouraged to wear masks for respiratory protection while welding.

SPIROMETRY

Routine spirometric measurements were conducted with a dry rolling seal spirometer (CHESTAC 65, Chest, Japan). The mechanical specifications and measurement procedure were identical to those described in detail elsewhere. ${ }^{14}$ Briefly, subjects were asked to repeat the forced expiration manoeuvre a maximum of seven times in the standing position to obtain acceptable, reproducible results. Routine correction for body temperature, ambient pressure, and saturation with water vapour (BTPS) and back extrapolation correction were carried out. The acceptability of each manoeuvre was evaluated according to the following criteria: starting without hesitation, apparent maximal effort, and smooth continuous exhalation without cough. Reproducibility was judged by the criteria of the American Thoracic Society, ${ }^{15}$ based on the measured values, and on the shape of flow volume and flow time curves. Subjects with at least two reproducible spirograms were considered to have provided reliable results. Vital capacity (VC) was measured in a routine way before the forced expiratory manoeuvre measurements. To minimise measurement bias, all examinations were carried out by one examiner with the same spirometer.

Forced vital capacity (FVC), forced expiratory volume in one second $\left(\mathrm{FEV}_{1}\right)$, maximal mid-expiratory flow (MMF), maximal expiratory flow at $50 \%$ and $25 \% \mathrm{FVC}\left(\mathrm{MEF}_{50}\right.$ and $\mathrm{MEF}_{25}$, respectively), and percentage rate of $\mathrm{FEV}_{1}$ divided by FVC $\left(\mathrm{FEV}_{1} \%\right)$ were calculated from the best manoeuvre with the largest sum of FVC and $\mathrm{FEV}_{1}$. Also, time domain analysis of forced spirograms was conducted to obtain peripheral lung region indices. As described elsewhere, ${ }^{16}$ the analysis provides two estimates of the assumed time constant distribution of lung peripheral units. One is $\mathrm{mu}$, which reflects the average component of the distribution, and the other is sigma, indicating their diversity component. When necessary, height squared $\left(\mathrm{ht}^{2}\right)$ proportional values were used for VC, FVC, $\mathrm{FEV}_{1}, \mathrm{MMF}$, $\mathrm{MEF}_{50}$, and $\mathrm{MEF}_{25}\left(\mathrm{VC} / \mathrm{ht}^{2}, \mathrm{FVC} / \mathrm{ht}^{2}, \mathrm{FEV}_{1} /\right.$ $\mathrm{ht}^{2}, \mathrm{MMF} / \mathrm{ht}^{2}, \mathrm{MEF}_{50} / \mathrm{ht}^{2}$, and $\mathrm{MEF}_{25} / \mathrm{ht}^{2}$ ) to adjust for difference in body size. ${ }^{17}$

\section{CHEST RADIOGRAPHIC FINDINGS}

Because they were mandatory in Japan, chest radiographic examinations of the subjects had been carried out periodically by the prescribed procedures. ${ }^{18}$ Based on the results of the most recent examination, the severity of findings in the lung fields of each subject was classified into 12 grades, from $0 /-$ to $3 /+$, which are compatible with the classification of the International Labour Organisation (ILO).
QUESTIONNAIRE SURVEY

A trained interviewer asked the subjects about respiratory symptoms, their past medical history, and lifetime smoking history with a standardised questionnaire of the American Thoracic Society (ATS-DLD-78-A) ${ }^{15}$ slightly modified and translated into Japanese. Workers were categorised into three subgroups according to their history of smoking; never smoker, former smoker, and current smoker at the time of this study. The number of cigarettes smoked a day was used as an index of smoking. All smokers in this study smoked cigarettes.

\section{MAGNETOPNEUMOGRAPHY}

To estimate accumulation of welding fumes in the lungs, the magnetisability of the subjects' lungs was evaluated in the following way. Firstly, the lungs of the subjects in a standing position were magnetised for 10 seconds with a 50-mT external static magnetic field generated by two electromagnets located in front and behind the chest. The subjects were then asked to immediately lie on a wooden bed in the supine position, and their chest was scanned with a fluxgate magnetometer positioned 10 $\mathrm{cm}$ above the top of chest surface. Rapid scanning was required in this field setting; the magnetometer used was a fluxgate type, which is less sensitive than a squid magnetometer, and there was very little time allowed for measuring any one person. Given these limitations, the strength of the residual magnetic field was measured over 16 prescribed areas in the chest and the largest value among them was recorded as the index of the lungs' magnetic field, denoted by LMF in the analysis.

\section{ANALYSIS}

Dose relatedness of pulmonary function indices according to the strength of the LMF was examined in the following way. Firstly, simple univariate regression of each pulmonary function index on the log transformed LMF was analysed. Then multivariate regression analyses were conducted to estimate the independent effect of log transformed LMF after controlling for age and smoking. In these analyses, the number of cigarettes smoked a day was used as the explanatory variable describing smoking dose. Interaction effects of the explanatory variables were examined by repeating analyses with various regression models and by including all possible combinations of the variables.

To compare the prevalence of chronic cough and chronic phlegm with smoking according to LMF strength, subjects were divided into three subgroups with a similar sample size by the LMF value; $\mathrm{LMF}$ was $<32$ microgauss in the low group, 32-109 in the middle group, and $\geqslant 110$ in the high group. Dose relatedness was tested by a routine $\chi^{2}$ test or Fisher's exact probability test.

Significance was judged as a $\mathrm{p}$ value $<0.05$ $(\alpha=0.05)$. All statistical tests and estimations were carried out with the SAS statistical packages at the Tokyo University Computer Centre. 


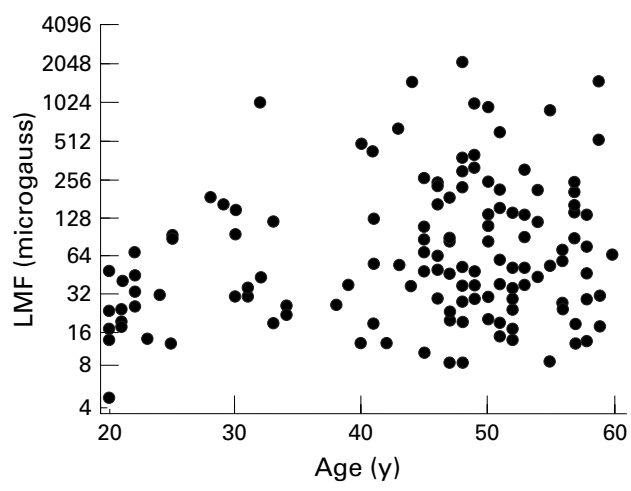

Figure 1 Distribution of strength of lung residual magnetic field (LMF) plotted against age. The ordinate is on a logarithmic scale.

\section{Results}

Three of the original 153 welders did not take the forced spirometry test because of ill health on the day of the examination. Five other subjects could not perform the forced spirometry acceptably, and another two could not provide reliable magnetopneumography measurements. Thus, a total of 10 workers were excluded from the analysis; however they constituted only $7 \%$ of the sample. Although four of the remaining 143 subjects had mild pulmonary fibrosis on their chest radiographic findings of $1 / 0$ to $1 / 2$ in the study year, preliminary analysis showed that excluding them from the analysis would not greatly influence any of the results. Therefore, the analysis was conducted on a total 143 welders $(93 \%$ of the original 153) in this study.

Figure 1 shows the distribution of LMF on the logarithmic scale according to age. There was a weak but significant positive relation between age and log transformed LMF $(r=0.24, \mathrm{p}=0.004)$. Because LMF was considerably skewed towards the positive and was extremely different from normality, LMF was used on a logarithmic scale in the statistical analyses.

Table 1 Description of the subjects analysed

\begin{tabular}{lcc}
\hline & Mean (SD) & Median (range) \\
\hline Age (y) & $45(11)$ & $48(20-60)$ \\
Engagement in welding (y) & $20(9)$ & $22(1-43)$ \\
Height (cm) & $167(6)$ & $166(149-181)$ \\
Weight (kg) & $62(8)$ & $61(46-85)$ \\
$\%$ VC $(\%)^{\star}$ & $97(13)$ & $97(70-138)$ \\
$\% \mathrm{FVC}(\%)^{\star}$ & $97(13)$ & $96(70-134)$ \\
$\% \mathrm{FEV}_{1}(\%)^{\star}$ & $96(13)$ & $96(59-129)$ \\
\hline
\end{tabular}

$\star \%$ Predicted values based on reference standard equations for a healthy Japanese man. ${ }^{19}$

Table 2 Prevalence of chronic cough and chronic phlegm, and relative frequency of smoking in the three groups according to LMF strength

\begin{tabular}{llcc}
\hline & \multicolumn{2}{l}{ LMF level } & \\
\cline { 2 - 4 } & Low $(n=48)$ & Middle $(n=47)$ & High $(n=48)$ \\
\hline Chronic cough & 0 & 8.5 & 14.6 \\
Chronic phlegm & 16.7 & 17.0 & 25.0 \\
Smoking: & & & \\
Never & 29.2 & 19.2 & 6.3 \\
Former & 18.8 & 10.6 & 12.5 \\
Current & 52.1 & 70.2 & 81.3 \\
\hline
\end{tabular}

${ }^{\star} \mathrm{p}<0.05$ by $\chi^{2}$ test or Fisher's exact probability test. LMF was $<32$ microgauss in the low group, $32-109$ in the middle group, and $\geqslant 110$ in the high group.
Table 3 Results of univariate regression analysis in which each of the pulmonary function indices was regressed on log transformed residual magnetic field (LMF)

\begin{tabular}{lll}
\hline & $\begin{array}{l}\text { Regression } \\
\text { coefficient }\end{array}$ & $\begin{array}{l}R^{2} \text { value of } \\
\text { the model (\%) }\end{array}$ \\
\hline $\mathrm{VC} / \mathrm{HT}^{2}\left(\mathrm{ml} / \mathrm{ml}^{2}\right)$ & $-2.9(9.0)$ & 0.1 \\
$\mathrm{FVC} / \mathrm{HT}^{2}\left(\mathrm{ml} / \mathrm{ml}^{2}\right)$ & $-1.1(9.6)$ & 0.01 \\
$\mathrm{FEV}_{1} / \mathrm{HT}^{2}\left(\mathrm{ml} / \mathrm{ml}^{2}\right)$ & $-15.6(9.0)$ & 2.1 \\
$\mathrm{FEV}_{1} \%(\%)$ & $-1.02(0.28)$ & 8.6 \\
$\mathrm{MMF}_{\mathrm{HTT}}\left(\mathrm{ml} / \mathrm{s}^{2} / \mathrm{m}^{2}\right)$ & $-52.4(18.1)$ & 5.6 \\
$\mathrm{MEF}_{50} \mathrm{HT}^{2}\left(\mathrm{ml} / \mathrm{s} / \mathrm{m}^{2}\right)$ & $-49.7(21.0)$ & 3.8 \\
$\mathrm{MEF}_{25} / \mathrm{HT}^{2}\left(\mathrm{ml} / \mathrm{s}^{2}\right)$ & $-28.1(9.7)$ & 5.6 \\
$\mathrm{Mu}(\ln (\mathrm{s}))$ & $0.045(0.014)$ & 7.9 \\
$\operatorname{Sigma}(\ln (\mathrm{s}))$ & $0.046(0.022)$ & 3.6 \\
\hline
\end{tabular}

^Per unit increase of $\log _{2}(\mathrm{LMF})$.

Descriptive characteristics of the subjects analysed are shown in table 1. Although cigarette smoking was common, the average $\mathrm{VC}, \mathrm{FVC}$, and $\mathrm{FEV}_{1}$ values of the subjects were well within the standard range of healthy Japanese populations. ${ }^{19}$ Table 2 shows the prevalence of chronic cough and chronic phlegm, and the current smoking status in the three subgroups according to LMF strength. Both of the symptoms and smoking habit became more prevalent as LMF increased.

Table 3 shows the results of the simple univariate regression analysis, in which each pulmonary function index was regressed on the log transformed LMF. Increases in LMF were significantly associated with reduced levels of function in $\mathrm{FEV}_{1} \%, \mathrm{MMF} / \mathrm{ht}^{2}, \mathrm{MEF}_{50} / \mathrm{ht}^{2}$, $\mathrm{MEF}_{25} / \mathrm{ht}^{2}, \mathrm{mu}$, and sigma.

Table 4 summarises the final results of the multivariate regression analysis. Third order interactions between age, smoking, and log transformed LMF were far from significant in all of the function indices. Among the second order interaction effects, the one between age and $\log$ transformed LMF showed borderline significance $(0.05<p<0.10)$ in the case of $\mathrm{FEV}_{1} \%$ and $\mathrm{mu}$. However, our preplanned level of $\alpha$ was 0.05 . As a result, the final regression model was a simple additive form of the effects of the three explanatory variables on all of the pulmonary function indices. As indicated in the table, only $\mathrm{FEV}_{1} \%$ and mu were still significantly associated with LMF after adjusting for age and smoking. Neither VC nor FVC showed a significant association with LMF. Percentage rate of $\mathrm{FEV}_{1}$ divided by FVC was expected to decrease by $0.6 \%$ for each doubling of LMF. Similarly, mu was expected to increase by 0.039 units, corresponding to about an $18 \mathrm{~ms}$ increase in average lung time constant. Figure 2 shows a scattergram of $\mathrm{FEV}_{1} \%$ and $\mathrm{mu}$ adjusted for age and smoking, plotted against LMF on the logarithmic scale. A linear regression line of each index against the log transformed LMF is also shown. This showed that the regression equation obtained provided a good fit to the overall data distribution.

If the regression model includes interaction effects between age and log transformed LMF, the effect of LMF will be dependent on age. Figure 3 shows the age dependent regression lines estimated for $\mathrm{FEV}_{1} \%$ and $\mathrm{mu}$ with this model. The influence of LMF was more evident in elderly people than in young subjects. 
Table 4 Independent effect of residual magnetic field (LMF) on pulmonary function indices after controlling for age and smoking dose $e^{\star}$, based on multivariate regression analyses (the final model used was a linear function of the independent effect of the three explanatory variables)

\begin{tabular}{lll}
\hline & $\begin{array}{l}\text { Regression } \\
\text { coefficient }\end{array}$ & $\begin{array}{l}\Delta R^{2} \neq \text { value } \\
\text { of the model (\%) }\end{array}$ \\
\hline $\mathrm{VC} / \mathrm{HT}^{2}\left(\mathrm{ml} / \mathrm{ml}^{2}\right)$ & $7.0(9.2)$ & 0.4 \\
$\mathrm{FVC} / \mathrm{HT}^{2}\left(\mathrm{ml} / \mathrm{ml}^{2}\right)$ & $12.0(9.4)$ & 1.0 \\
$\mathrm{FEV}_{1} / \mathrm{HT}^{2}\left(\mathrm{ml} / \mathrm{ml}^{2}\right)$ & $1.3(8.1)$ & 0.02 \\
$\mathrm{FEV}_{1} \%(\%)$ & $-0.63(0.27)$ & 2.8 \\
$\mathrm{MMF}_{\mathrm{H}} \mathrm{HT}^{2}\left(\mathrm{ml} / \mathrm{s} / \mathrm{m}^{2}\right)$ & $-25.2(17.8)$ & 1.1 \\
$\mathrm{MEF}_{50} / \mathrm{HT}^{2}\left(\mathrm{ml} / \mathrm{s}^{2}\right)$ & $-27.2(22.0)$ & 1.0 \\
$\mathrm{MEF}_{25} / \mathrm{HT}^{2}\left(\mathrm{ml} / \mathrm{s} / \mathrm{m}^{2}\right)$ & $-6.3(8.0)$ & 0.2 \\
$\mathrm{Mu}(\ln (\mathrm{s}))$ & $0.039(0.016)$ & 5.0 \\
Sigma $(\ln (\mathrm{s}))$ & $0.008(0.019)$ & 0.1 \\
\hline
\end{tabular}

* Number of cigarettes smoked a day was used as an index of the smoking dose.

+ Per unit increase of $\log _{2}$ (LMF).

\# Increase in $\mathrm{R}^{2}$ value when adding the variable $\mathrm{LMF}$ to the model.

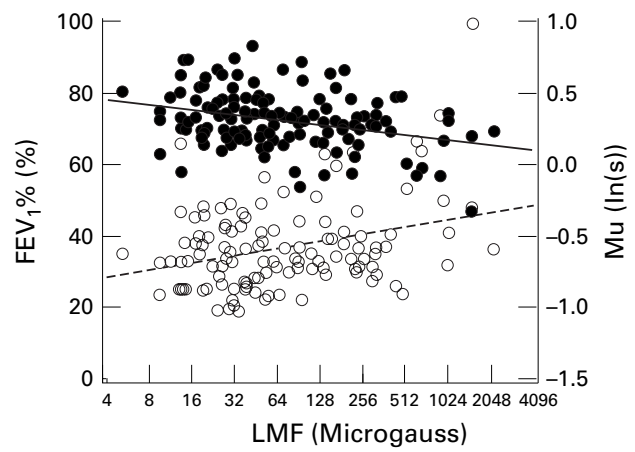

Figure 2 Scattergram of $F E V_{1} \%$ (closed circles) and $m u$ (open circles) plotted against $L M F$, after adjustment for age and smoking status, by analysis of covariance. Values were calculated on the assumption that the subjects were never smokers and 45 years old, the average age of this population. The abscissa is on a logarithmic scale. Two straight lines show the simple linear regression of each pulmonary function index on $\log _{2}(L M F)$.

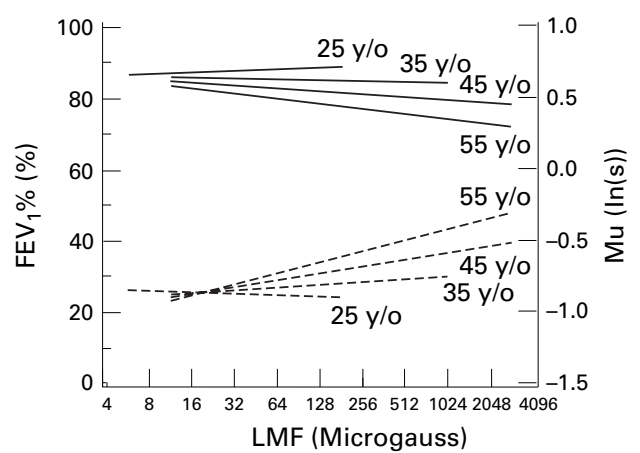

Figure 3 Age dependent effect of LMF on FEV $\%$ (full lines) and mu (hatched lines) estimated in a linear model in which the interaction effect between age and log transformed $L M F$ was included as well as the independent effect of the two variables and smoking dose. The four lines indicate for the predicted equations for non-smoking men aged $25,35,45$, and 55, respectively.

\section{Discussion}

One of the difficulties in investigating the chronic respiratory effect of welding work is assessment of exposure. Although the environment of welding workplaces is currently fairly well maintained in most developed countries, most welders must have experienced relatively high levels of exposure in the past. Furthermore, actual exposure while welding is greatly influenced by factors related to individual workers such as posture, technical skill, protection by breathing masks and their goodness of fit to the face, and other factors, while welding. It is therefore difficult to accurately estimate the actual exposed dose of individual workers based on work history or work environment records. This applies especially to the assessment of cumulative exposure. There could be considerable differences in cumulative exposure of welders with similar work backgrounds.

Magnetopneumography, devised by Cohen et $a l,{ }^{20}$ measures the magnetisability of lungs by an external source. Because the normal constituents of the human body have little magnetisability, magnetopneumography measurements are considered to reflect the amount of material inhaled, if it is sufficiently magnetisable and relatively homogeneous. Several studies have used this method to estimate the lung dust deposition in various types of workers, such as welders, miners, asbestos workers, and others. ${ }^{21-23}$ Among them, welders have shown the highest level of lung magnetisability. ${ }^{21}$ Subjects without occupational exposure to dust showed negligible or low activities of lung magnetisability compared with welders. ${ }^{21}{ }^{22}$ No lifestyle factors are known to result in measurable magnetisability, although smoking can delay the lung clearance of magnetisable dust in occupationally exposed workers. ${ }^{24}$

In this study, a significant association was found between LMF strength and obstructive pulmonary function indices. Most subjects processed mild steel by electric arc welding with an inert gas shield. The similarity of the material processed and the welding methods make it possible to consider the constituents of the fumes generated to have been relatively homogeneous. Furthermore, because of the lifelong employment system in Japan, most workers were thought to have welded only in their present company. Thus, it can be assumed that LMF strength reflects the amount of welding fumes accumulated in the lungs fairly well. That this dose related difference in pulmonary function will still present after controlling for possible confounders is additional evidence supporting the hypothesis that chronic accumulation of welding fumes is related to obstructive changes in pulmonary function. It should be stressed that current work environment of the factory in this study was acceptably maintained and that most of the workers had no abnormal chest radiographic findings.

Several previous studies have described abnormalities of pulmonary function only in welders who smoked. Smoking is a possible source of bias in this study, because it both decreases lung clearance of inhaled particles, ${ }^{24}$ and adversely affects pulmonary function. Because of the few subjects in this study, it was impossible to analyse the data separately by smoking. However, $\mathrm{FEV}_{1} \%$ and mu were still significantly associated with LMF after controlling for the difference in smoking among the subjects as a whole.

One interesting finding in this study was that better $\mathrm{FVC} / \mathrm{ht}^{2}$ could be expected as LMF 
increased, after adjusting for age and smoking. On the other hand, no difference in $\mathrm{FEV}_{1} / \mathrm{ht}^{2}$ was found, resulting in significantly reduced $\mathrm{FEV}_{1} \%$. As forced spirometry is primarily effort dependent, both FVC and $\mathrm{FEV}_{1}$, and therefore $\mathrm{FEV}_{1} \%$, are vulnerable to poor performance of the forced expiration manoeuvre. In this study, however, mu, a mean component of assumed time constant distribution of peripheral lung units, was also significantly associated with LMF. Although both $\mathrm{FEV}_{1} \%$ and $\mathrm{mu}$ are sensitive to obstructive changes in airways and are theoretically independent of lung size, they reflect somewhat different aspects of the forced spirogram: $\mathrm{FEV}_{1} \%$ is more sensitive to the early portion which is effort dependent, whereas mu is more sensitive to events in the relatively terminal portion, which is independent of effort. These considerations suggest that the obstructive change found was not due to measurement error. Mild exposure to welding fumes may result in increased lung volume (FVC) to maintain the $\mathrm{FEV}_{1}$ level.

There are several sources of bias which could explain the results of this study. Firstly, the use of heavy welding equipment may result in a training effect on the accessory muscles of respiration. This could explain the association between high LMF level and reduced $\mathrm{FEV}_{1} \%$ with slightly increased FVC/ht ${ }^{2}$. Selection bias may be another explanation because heavier exposure may have selected for those with better pulmonary function and larger lung volumes. It should also be pointed out that the effect of harmful gases associated with welding was not taken into consideration. As a conventional protection mask for welders does not necessarily reduce gaseous exposure, it is reasonable to consider that the subjects with low LMF may have high cumulative exposure to harmful gases. This might also bias the results of this study. Follow up of these workers and longitudinal comparison of decline in $\mathrm{FEV}_{1}$ will provide useful information about this. Finally, we should consider the generalisability of this study. Although acceptable measurements of magnetopneumography and pulmonary function were carried out in $>90 \%$ of the sample, the number of the analysed subjects was only 143 . Furthermore, the subjects were derived from one factory where the working environment was well maintained. Therefore, the generalisability of the findings in this study should be confirmed by studying welders working under various working conditions.

In conclusion, the results of this study showed that obstructive changes in pulmonary function were related to cumulative exposure in male Japanese welders after controlling for age and smoking, assuming that magnetopneumography measurements accurately reflect accumulation of welding fumes in the lungs. Because of its cross sectional nature, follow up of this population is needed to elucidate the possible causes of chronic engagement in electric arc welding in obstructive airway disease.

1 Speizer FE. The rise in chronic obstructive pulmonary disease mortality. Am Rev Respir Dis 1989;140:S1-107.

2 Report of a World Health Organisation Expert Committee. Identification and control of work-related diseases. Geneva: WHO, 1985:25-30. (Technical report series 714.)

3 Morgan WKC. On welding, wheezing, and whimsy. Am Ind Hyg Assoc ₹ 1989:50:59-69.

4 Sjogren B, Ulfvarson U. Respiratory symptoms and pulmonary function among welders working with aluminum, stainless steel and railroad tracks. Scand $\mathcal{f}$ Work Environ Health 1985;11:27-32.

5 Mur JM, Teculescu D, Pham QT, et al. Lung function and clinical findings in a cross-sectional study of arc welders. Int Arch Occup Environ Health 1985;57:1-17.

6 McMillan, Pethybridge RJ. A clinical , radiological and pulmonary function case-control study of 135 dockyard welders aged 45 years and over. Fournal of the Society of Occupational Medicine 1984;34:3-23.

7 Hayden SP, Pincock AC, Hayden J, et al. Respiratory symptoms and pulmonary function of welders in the engineering industry. Thorax 1984;39:442-7.

8 Antti-Poika M, Hassi J, Pyy L. Respiratory diseases in arc welders. Int Arch Occup Environ Health 1977;40:225-30.

9 Parkes WR. Occupational lung disorders, 3rd ed. Oxford: Butterworth-Heinemann, 1994:248.

10 Wolf C, Pirich C, Valic E. Pulmonary function and symptoms of welders. Int Arch Occup Environ Health 1997; 69:350-3.

11 Kilburn KH, Warshaw RH. Pulmonary functional impairment from years of arc welding. Am f Med 1989;87:62-9.

12 Oxhoj $\mathrm{H}$, Bake B, Wedel $\mathrm{H}$, et al. Effects of electric arc welding on ventilatory lung function. Arch Environ Health 1979;34:211-7.

13 Japan Society for Occupational Health. Recommendation on threshold limit values. Sangyo Eiseigaku Zasshi 1996;38: on threshold limit value.

14 Nakadate T, Sato T, Kagawa J. Longitudinal changes in time domain spirogram indices and their variability. Eur Respir $\mathcal{F}$ 1994;7:1062-9.

15 Ferris BG. Epidemiology standardization project. Am Rev Respir Dis 1978;118:1-120.

16 Permutt S, Menkes HA. Spirometry. Analysis of forced expiration within the time domain. In: Macklem P, Permutt $\mathrm{S}$, eds. The lung in the transition between health and disease. New York: Marcel Decker, 1977:113-52.

17 Nakadate T. Decline in annual lung function in workers exposed to asbestos with and without pre-existing fibrotic changes on chest radiography. Occup Environ Med 1995;52: changes on

18 Department of Safety and Health, Ministry of Labor, Japan. Handbook for health examination on pneumoconiosis. Tokyo: Japan Safety and Health Association, 1978:31-9. (In Japanese.)

19 A Committee on pulmonary physiology. Reference values of pulmonary function in healthy fapanese population. Tokyo: Japan Society of Thoracic Disease, 1993:1-25. (In Japanese.)

20 Cohen D. Report of the low-field group: the magnetic field of the lung. Francis Bitter National Magnet Laboratory, MIT, 1978:1-268.

21 Freedman AP, Robinson SE, O'Leary K, et al. Non-invasive magnetopneumographic determination of lung dust loads in steel arc welders. Br f Ind Med 1981;38:384-8.

22 Freedman AP, Robinson SE, Johnston RJ. Non-invasive magnetopneumographic estimation of lung dust loads and distribution in bituminous coal workers. $f$ Occup Med 1980;22:613-8.

23 Kalliomaki PL, Kalliomaki K, Korhonen O, et al. Respiratory status of stainless steel and mild steel welders. Scand $\mathcal{F}$ Work Environ Health 1982;8(suppl 1):117-21.

24 Cohen D, Arai SF, Brain JD. Smoking impairs long-term dust clearance from the lung. Science 1979;204:514-7. 